\title{
Mentoring Women Students in Engineering: Lessons Learned from the Sociology of Gender
}

\author{
Naomi C. Chesler, Mark A. Chesler \\ University of Vermont/University of Michigan
}

\begin{abstract}
Women in engineering who seek mentoring relationships face a number of special challenges and obstacles. Interpersonally- and institutionally-generated gender dynamics make the construction and maintenance of mentoring relationships especially difficult. Mentoring of both female and male students can be enhanced by recognizing the different cultural styles of women and men, the needs of women (and many men) for supportive and nurturing relationships in the midst of a highly competitive educational system. Mentoring strategies that fit more readily with a female cultural worldview, according to well-accepted theories on the sociology of gender, are peer-, multiple- and collective mentorships. Mentoring of women must also acknowledge the socially-constructed dynamics of gender that affect cross-gender relationships and respond to the special ways in which women must often balance career and family relationships. Successful mentoring of women rests on, and can help create, a caring community in which women (and men) have equal access to all educational resources including those relevant to their psychosocial as well as technical growth and success.
\end{abstract}

\section{Introduction}

In 1995, women constituted $46 \%$ of the U.S. labor force, but only $22 \%$ of the scientists and engineers. ${ }^{1}$ Male scientists and engineers were more likely than women to earn a higher salary, to be employed full time and to be employed in their field of highest degree ${ }^{1}$. In 1998, women graduates of engineering programs represented just $18.6 \%$ of the undergraduate, $20.3 \%$ of the masters and $12.3 \%$ of the doctoral degrees in the U.S. ${ }^{2}$ Mentoring women undergraduate students may be a promising strategy for improving their presence, retention and advancement in engineering disciplines. Indeed, quantitative studies on mentor functions and outcomes in organizations have shown that both formal and informal mentoring relationships are effective in promoting protégé advancement and compensation. ${ }^{3,4}$

Mentoring is traditionally a developmental relationship in which an experienced person provides support to a less experienced person. In return, the mentor gains personal satisfaction, respect from colleagues for successfully developing the younger talent, and in the best case grows intellectually as well. Mentoring has multiple aspects and functions, and has variously been described as fulfilling either or both the technical and psychosocial needs of the less experienced person. Examples of the technical knowledge-based or career development issues include how to solve a particular technical problem, continue intellectual growth, approach a new internship, job or course, develop a syllabus or field project, prepare a research proposal, balance work overloads, present an appeal to a faculty member or department chair, ask for an assignment change, learn the "unwritten rules" of the organization (e.g., dress codes, address titles, social 
styles and norms), etc. Mentors and protégés also may address psychosocial issues such as how to deal with difficult peer or faculty relationships or personality conflicts, balance school, work and family pressures, respond to sexism and discrimination, establish a sense of competence, cope with disappointment, find courage, grow as a person, etc. The traditional conception of mentoring poses accomplishing such objectives within a two-person, mentor-protégé relationship. 5

\section{Relevant socialized gender differences}

Socialized gender differences between men and women have significant implications for careers in engineering. Such differences begin to take shape in differential child-rearing patterns and are reinforced in the "hidden curriculum" of elementary and secondary schooling. ${ }^{6}$ Through schooling, young boys and girls learn different lessons about their competencies, gendered roles and styles, and life/career aspirations. Girls are less likely than boys to take advanced science courses in school and eventually are more likely to rate themselves as less competent and less interested than boys in fields like engineering. ${ }^{7-9}$ These patterns are supported (if not created) by public pronouncements from as renowned a psychologist as Bruno Bettelheim, who argued that: "We must start with the realization that, as much as women want to be good scientists and engineers, they want first and foremost to be womanly companions of men and to be mothers" (quoted in [6], p. 120).

As a result of these socialization and early education experiences, young women have been taught to place greater priority interpersonal satisfaction and integration than do men, potentially resulting in different career (and life) priorities. ${ }^{10}$ Moreover, women more often prioritize concerns for group affiliation over individual achievement and value egalitarianism, community, collaboration and diversity more than their male counterparts. ${ }^{11,12}$ An encapsulation of socialized gender differences between women and men in our culture is given in Table 1. We readily acknowledge that this rubric does not apply to everyone; there are important variations across racial and class groupings, and a bell-curve distribution likely exists allowing significant individual variation and crossover between socialization patterns.

Table 1. Outcomes of socialized gender patterns on characteristics and goals (from [10]).

\begin{tabular}{|l|l|l|}
\hline & Female & Male \\
\hline Motivation & Encouragement & Challenge \\
\hline Group Interaction & Integrated & Separated \\
\hline Task Engagement & Collaborative & Competitive \\
\hline Vision of Success & Group Affiliation & Individual Achievement \\
\hline
\end{tabular}

The differential socialization of women and men is particularly relevant to their success in the sciences and engineering, because women are often less confident in and alienated by the culture of disciplines which do not fit well with their cultural style. That SME education emphasizes individual competition and offers few opportunities for cooperative and interactive learning, and thereby can be considered "gendered", and in particular, to embody a male cultural style, may contribute to the absence of women in SME disciplines. ${ }^{13,14}$

\footnotetext{
* It is worth noting here that the gendered nature of a profession or any organization may be invisible to both men and women. Indeed "gender may be deeply hidden in organizational processes and decisions that appear to have
} 
In a 1995 report, the National Research Council Board on Engineering Education emphasized the importance of creating a positive, supportive climate for engineering students as an alternative to the "boot camp" or "weed out" nature of some engineering programs. In particular, the Council cites Carmichael and Sevenair ${ }^{15}$ in recognizing that women and under-represented minority students "may be even more put off than others by the boot camp atmosphere prevalent in undergraduate engineering education." Along similar lines, Seymour \& Hewitt argue that "more women than men found the one-size fits all psychology that underwrites the competitive ethos of SME majors alien or offensive" ([16], p. 121). Adverse reactions to negative pedagogical and peer group experiences leads to higher "switch rates" (rates at which majors in SME switch to other majors) among women students as compared to male students with similar grades. ${ }^{17,18}$ Anecdotal evidence suggests many men find women students in engineering "unnatural" or unfeminine, marginalizing them through the use of pejoratives such as ugly, sexually deviant or "too busy to be attractive." 14 When these perceptions and related behaviors are acted out in the classroom, hallways and laboratories, and tolerated by student peers, faculty and staff, they are reinforced in the lives of both men and women.

These barriers and disincentives prevent young women from entering SME fields and contribute to the "leaky pipeline" of women in engineering at both the undergraduate and graduate level. ${ }^{14}$ Thus, one technique for increasing the number of women who enter and stay in engineering is to create a supportive learning environment with approachable, accessible faculty and a deemphasis on "masculinist" organizational styles, which emphasize hierarchy, individualism and competition.

II. Mentoring according to a male cultural style

In the context of the male-dominated academy, especially in the sciences and engineering, the mentoring of both male and female students generally has proceeded on the basis of a male cultural style. Two major components typify this approach to mentoring: (1) the priority of instrumental and technical conversation, relationships, and guidance over psychosocial issues; and (2) the commitment to "the heroic journey" or "the challenge." Research with young men and women in science and engineering suggests that men have "a predominantly instrumental approach to education...contrasted with an affective orientation among many young women" ([16], p. 464). Thus, the mentoring model that emphasizes technical and instrumental issues is well suited to the preponderance of traditionally-socialized men in these fields; at the same time, it does not fit well with the ways in which women were socialized.

The male socialization metaphor underpinning most traditional mentoring relationships focuses on challenging the protégé and, as Seymour describes, posing tasks in order to increase the young person's tolerance to stress, ability to succeed independently ${ }^{16}$ and potentially to weed out those who cannot rise to the challenge. Broome ${ }^{19,20}$ applies the works of Robert Bly and Joseph Campbell in discussing "the heroic engineer" and "the heroic mentorship." The hero's journey, in this interpretation, requires separation from dependency - including abandonment by former helpers, sole engagement in perilous adventure, and triumphant return. As Broome indicates, on

nothing to do with gender" but are "embedded and recreated daily in organizational activities, most of which do not appear to be gendered" (p. 71, [12]). See [12] for further discussion. 
this journey "the helper abandons the hero, leaving him or her eventually to slay the dragon" ([20], p. 415). The denial of nurturing in the midst of stressful situations is presumed to lead to healthy independence and stems from traditional "tests of manhood" present in military and sport arenas. It also often leads to the highly competitive situation that Baum ${ }^{21}$ has called "the boot camp environment where one's success comes only at the failure of others." Reconsidering the gender patterns outlined in Table 1, this style clearly does not fit the socialization and styles of most women, in particular their orientations to integration rather than separation, interdependence rather than dependence or independence, and collaborative rather than competitive task engagement. Perhaps not as obviously, it also does not fit well for many younger men who are now being socialized in less gender-constricted ways.

\section{Alternative mentoring strategies}

$\underline{\text { Multiple mentorships }}$

In an alternative model that can be conceptualized as a Venn diagram of interconnected circles, multiple mentoring encourages the protégé to construct a mentoring community based on a diverse set of helpers instead of relying on a single mentor. Humphreys ${ }^{22}$ discusses the possibilities of "distributed mentorship", which includes as mentors both senior and junior colleagues, people inside as well as outside the academy, and electronic media as well as personal connections. Similarly, in a series of pamphlets recently created by the University of Michigan, mentors are advised "to help students cultivate multiple mentoring relationships inside and outside the university" ([23] p. 6). A parallel pamphlet prepared for potential protégés, advises students to build "a mentoring team", and reminds them that "by having a team of mentors, you will not be harmed in any way if you work with someone who truly has limited access to the powerful networks of your discipline" ([24], p. 39).

Galbraith \& Maslin-Ostrowski argue for the importance of long-term mentoring of students by a mentoring team. They point out that it is "reasonable to expect that if the mentor team members are given the responsibility for teaching entry-level required courses, then they may begin to establish a relationship with future mentees early in the students' academic careers. This would be accomplished in part through active listening and questioning that establishes a psychological climate of trust. This trust lays the foundation for a more engaging mentoring relationship. Without this type of connection, the likelihood of a meaningful mentor-mentee experience is limited." 25

Some of these ideas have been tested by Packard, ${ }^{26}$ who has devised an intervention program aimed at helping protégés assemble a diverse set of mentors into a "composite mentor." Suggesting that young scholars consider the attractive traits of different role models in their environment, she argues that the composite mentor is especially promising for women in SME: because they "struggle with the lack of mentor images in the field... It would help women make use of the available images in their environment," ([26], p. 5.) including men and people from different backgrounds. The disadvantage of this approach is that the burden of community building is laid upon the protégé. And finding a diverse set of helpers who meet the various and changing needs of the protégé in a new institution or new career stage is not a trivial task. 


\section{Peer mentoring}

Peer mentoring represents another alternative mentoring strategy that simultaneously builds community and de-emphasizes seniority and hierarchy. It has also been held up as a strategy that "may embody a more feminist construct for promoting women in academia" ([27], p. 94). Female friendship circles and study groups may help women SME students learn material and support one another while avoiding constant competition or negative interactions with men. Limbert has described her personal experiences in a group for academic faculty and staff women that encourages support "across boundaries and disciplines, ... [and] between disciplines and/or departments." ([28], p. 95) In addition to the development of a broad and diverse professional community, Limbert promotes the flexibility and informality of peer mentoring relationships that enable women to "drop in and drop out." More generally, this flexibility in time and level of commitment directly addresses problems women often experience with the traditional mentoring model; that is, unpredictable family and child-care responsibilities and career interruptions. While peer mentoring strategies are worth further study, Chandler has predicted three main obstacles to their long-term success which all arise from the abolition of the traditional hierarchy: "The competitive position that peers often find themselves in, lack of experience, and the difficulty that may arise if their careers [or studies] advance at different rates" ([27], p. 95). Struggle over whose needs are met when is another possible complication in the multiple mentor/multiple mentee strategy relying on peers.

\section{Collective mentoring}

Collective mentoring is an evolution of the multiple mentor/single mentee model whereby the entire faculty of a department take responsibility for constructing and maintaining a mentoring team. Thus, mentoring becomes neither an individual or one-on-one activity, nor one solicited and designed solely by the protégé. Instead, an entire department or organization must establish and ensure the effective mentoring and performance of young students. In this way, senior faculty and the department itself send the message that their progress is a priority concern and may create a departmental climate that overcomes some of the obstacles not only to effective mentoring of women, but also to their effective performance, retention and advancement. As Seymour and Hewitt argue, an effective program must have a "public commitment of senior administrators and departmental chairs. Successful programs draw upon the knowledge of senior women students and female faculty who know how the culture of S.M.E. departments work. They also employ the help of sympathetic male faculty as a network of mentors from professional work settings" ([16], p. 275).

Tierney \& Bensimon ${ }^{29}$ point out that collective mentoring is a formal and collective organizational task, part of the organization's responsibility to orient and socialize its new members. As such, "Mentoring need not take place only in a senior faculty member's office or an orientation session at the beginning of the school year. The mail room, the faculty lounge, [or dormitories, cafeterias, study rooms] and any number of other institutional locations have potential for socializing individuals to the culture of the department and organization." ([29], p. 56). Transformation that creates more egalitarian and caring educational communities will benefit men as well as women. 


\section{Creating opportunities for alternative mentoring}

\section{Early mentoring}

Since many of the patterns that channel young women away from exploring careers in science, math and engineering, or that discourage them from pursuing such paths when they do have an interest, occur early in their education, mentoring programs must intervene at an early stage. In a number of middle and secondary school systems steps now are being undertaken to counter gender discrimination in math and science curricula and instruction. The Keys to Empowering Youth (KEYS) program begun at MIT is one such example. ${ }^{30} \mathrm{KEYS}$ is now a national, motivational program for 11 to 13 year old girls that provides them with an opportunity to meet and interact with women studying and working in science and engineering in one or two-day programs that focus on hands-on, engineering-oriented activities.

At the University of Michigan, a social science twist on this idea has led to the development of the UM-GIRL (Using Math: Girls Investigate Real Life) ${ }^{31}$ program. Here, middle-school girls who have an interest in and an aptitude for SME learn math and computer skills during a summer session and then conduct statistical analyses on current social scientific data sets that investigate gender issues. These students and their teachers are teamed with female graduate student mentors who train the girls and assist with the analysis throughout the following year. The content of the data set is interesting as well as provocative for the middle school girls; the presence of female role models is especially advantageous; and the linkage between the teachers and the academic mentors ensures continuation of the technical and symbolic lessons learned throughout the year.

\section{Mentoring at the college-level}

In the collegiate environment as well, early mentoring and support for women who have an interest in engineering would be helpful. Student organizations that recruit from all engineering disciplines and years are excellent opportunities to initiate peer mentoring. Engineering-only dormitory suites, organized by the college or university, similarly foster informal and continual interactions between senior and underclass women that may lead to mentoring communities. The impact of these interactions on underclasswomen could be enhanced with formal mentoring training of the upperclass women in these organizations or dormitory groups. National meetings of special-interest engineering societies (such as SWE, NSBE, SHPE, etc.) are also excellent opportunities for developing peer communities and mentoring groups. Again, providing senior members of these organizations with formal training in mentoring as well as media or resources for continued contact (email listserves or budget for a newsletter) may synergistically enhance their ability to form and maintain mentoring relationships with other members.

Multiple and collective mentoring of women students in engineering requires the support and direction of the department or college. Since the multiple mentoring strategy is predominantly based on the initiative of the mentee, the departmental requirements are minimal. At the least, incoming students should be made aware of the benefits of mentoring and encouraged to seek out suitable student, faculty or professional mentors. If possible, students should be given a list of potential mentors on and off-campus, and made aware of e-mentoring opportunities (such as MentorNet, if available). The construction of a collective mentoring program further requires departmental supervision of and commitment to the mentee's developing mentor-network, and assessment of and feedback to the mentors themselves. 


\section{Conclusions}

We have argued that mentoring is an important component of efforts to improve the presence, retention and advancement of women in engineering, and that women students in SME who seek mentoring relationships face a number of special challenges and obstacles. Some of these obstacles are generated by men and women's prior socialization, expectations and styles. Some are generated by peer gender dynamics and by the dynamics of inter-status mentoring across gender lines. And some are generated and reinforced by the culture, work expectations and reward systems of the male-dominated academy. Successful mentoring of women in SME must recognize the different cultural styles or worldviews of men and women, the diverse needs and styles of women from different cultural and class backgrounds, the needs of women (and many men) for supportive and nurturing relationships in the midst of a highly stressful and competitive profession, and the socially constructed and institutionally supported dynamics of gender privilege that affect cross-gender relationships. While attention has begun to be paid to the special interpersonal sensitivities and tactics that might be important in mentoring women students, our particular concern is with alternative models of the mentoring relationship itself, especially ones that originate from and cater to women's cultural styles.

\section{Bibliography}

1. Women, Minorities and Persons with Disabilities in Science and Engineering. 1999, National Science Foundation: Arlington, VA.

2. American Association of Engineering Societies. (1998). Engineering and Technology Degrees. Washington, DC: Author.

3. Ragins, B. and J. Cotton (1999). Mentor functions and outcomes: A comparison of men and women in formal and informal mentoring relationships. Journal of Applied Psychology 84(4): 529-550.

4. Muller, C. B. and P. B. Single (2000). MentorNet: The National electronic industrial mentoring program for women in engineering and science.

5. Clark, S. and M. Corcoran, Perspectives on the professional socialization of women. Journal of Higher Education, 1986. 57(1): p. 20-43.

6. Frazier, N., \& Sadker, M. Sexism in School and Society. New York, Harper \& Row. 1973.

7. AAUW (American Association of University Women). Gender Gaps: Where Schools Still Fail Our Children. Washington, DC. American Association of University Women Educational Foundation. 1998.

8. National Science Board. Science and Engineering Indicators-1996 (NSB-96-21). Washington, DC. 1996.

9. Smith, T. Findings from the condition of education. In The Educational Progress of Women. Washington, DC. National Center for Educational Statistics. 1995.

10. Gilligan, C., In a different voice: Psychological theory and women's development. 1982, Cambridge, MA: Harvard University Press.

11. Helgesen, S., Female Advantage: Women's Ways of Leadership. 1995, New York, NY: Doubleday Currency.

12. Maier, M., On the Gendered substructure of organization, in Handbook of Gender \& Work, G.N. Powell, Editor. 1999, Sage Publications: Thousand Oaks, CA.

13. Ginorio, A. A culture of meaningful community. in Bridging the Gender Gap in Engineering and Science. 1995.

Carnegie Mellon University, Pittsburgh, PA.

14. Seymour, E., The loss of women from science, mathematics and engineering undergraduate majors. Science Education, 1995. 79(4): p. 437-473.

15. Carmichael, J.W.J. and J.P. Sevenair, Preparing minorities for science careers. Issues in Science and Technology, 1991. 7(3): p. 55-60.

16. Seymour, E. and N. Hewitt, Talking About Leaving: Why undergraduates leave the sciences. Vol. 79. 1997, Boulder, CO: Westview Press. pp 437-473.

17. Strenta, C., et al., Choosing and leaving science in highly selective institutions: General factors and the question of gender, . 1993, Report to the Alfred P. Sloan Foundation. 
18. Astin, A. and H. Astin, Undergraduate Science Education: The impact of different college environments on the educational pipeline. 1993, Los Angeles, CA: UCLA Press.

19. Broome, T., The Heroic mentorship. Science Communication, 1996. 17(4): p. 398-429.

20. Broome, T., The Heroic engineer. Journal of Engineering Education, 1997. 86(1): p. 51-55.

21. Baum, E. Setting the Stage. in Bridging the Gender Gap in Engineering and Science. 1995. Carnegie Mellon University, Pittsburgh, PA.

22. Humphreys, S. The role of women graduate students. in Bridging the Gender Gap in Engineering and Science. 1995. Carnegie Mellon University, Pittsburgh, PA.

23. Rackham School of Graduate Studies, How to Mentor Graduate Students, . 2000, University of Michigan: Ann Arbor, MI.

24. Rackham School of Graduate Studies., How to Get the Mentoring You Want, . 2000, University of Michigan: Ann Arbor. MI.

25. Galbraith, M.W. and P. Maslin-Ostrowski, Chapter Six: The Mentor Facilitating Out-of-Class Cognitive and Affective Growth, in Teaching Alone, Teaching Together: Transforming the structure of teams for teaching, James L. Bess and Associates, Editor. 2000, Jossey-Bass: San Francisco, CA. p. 145-148.

26. Packard, B. A "composite mentor" intervention for women in science. in American Educational Reserach Association Annual Meeting. 1999. Montreal, QC.

27. Chandler, C., Mentoring and Women in Academia: Reevaluating the traditional model. NWSA Journal, 1996. 8: p. $79-100$.

28. Limbert, C., Chrysalis, A Peer mentoring program for faculty and staff women. NWSA Journal, 1995. 7: p. 8699.

29. Tierney, W. and E. Bensimon, Promotion and Tenure: Community and Socialization in Academe. 1996 , Albany, NY: State University of New York Press.

30. http://psc.mit.edu/keys/index.html

31. See for exa mple http://www.umich.edu/ irwg/newsletter/girls.html

\section{NAOMI C. CHESLER}

Naomi Chesler is currently an Assistant Professor of Mechanical Engineering at the University of Vermont. She received her B.S. in General Engineering from Swarthmore College, M.S. in Mechanical Engineering from MIT and Ph.D. in Medical Engineering from the Harvard-MIT Division of Health Sciences and Technology. In addition to her research into the clinically relevant effects of mechanical forces on vascular biology, Dr. Chesler teaches dynamics, fluid dynamics and biofluid dynamics at the undergraduate and graduate levels.

\section{MARK A. CHESLER}

Mark Chesler is a Professor of Sociology at the University of Michigan, former Director of Graduate Studies and current Director of Undergraduate Studies in that department. He has published widely in the area of race and gender discrimination in higher education and the impact of chronic childhood illness on the family. 